\title{
THE JOSIAH WILLARD GIBBS LECTURESHIP
}

The Council of the Society has sanctioned the establishment of an honorary lectureship to be known as the Josiah Willard Gibbs Lectureship. The lectures are to be of a popular nature on topics in mathematics or its applications, and are to be given by invitation under the auspices of the Society. They will be held annually or at such intervals as the Council may direct. It is expected that the first lecture will be delivered in New York City during the winter of 1923-24, and a committee has been authorized to inaugurate the lectures by choosing the first speaker and making the necessary arrangements.

R. G. D. Richardson, Secretary.

\section{AN ELECTROMAGNETIC THEORY OF LIGHT-DARTS}

BY H. BATEMAN

1. Introduction. Since Einstein's theory of light-quanta * is being carefully tested in many ways by ingenious experiments and is gaining favor, it is thought by some physicists that in the future Maxwell's equations will no longer be regarded as the best starting point for the elucidation of physical phenomena but will be derived from the equations of quantum-theory by some limiting process.

On the other hand, it may be argued that physicists have been led to this point of view because they refuse to believe what is clearly indicated by some of the most interesting solutions of Maxwell's equations. These solutions show that

* A. Einstein, Annalen der Physik, vol. 17 (1905), p. 132; PhysikalISCHe Zeitschrift, vol. 10 (1909), p. 185; vol. 18 (1917), p. 121. 